\title{
PEMBUATAN ALAT MONITORING SUHU DAN DAYA LISTRIK YANG DAPAT DIBACA SECARA ONLINE PADA ANECHOIC CHAMBER DI LABORATORIUM ANTENA POLITEKNIK NEGERI PADANG
}

\author{
Anggara Nasution ${ }^{1 *}$, Rusfandi $^{2 *}$, Roni Putra ${ }^{3 *}$ \\ 1,2,3, Jurusan Teknik Elektro, Politeknik Negeri Padang \\ Gedung G Lantai 3, Kampus Politeknik Negeri Padang, Padang - 72590 \\ *E-mail : bangangga81@gmail.com ${ }^{1}$
}

\begin{abstract}
Abstrak
Tujuan dari pembuatan alat ini adalah untuk membangun komunikasi data untuk pengumpulan informasi mengenai kondisi suhu kelembaban dan penggunakan energy listrik anechoic chamber di laboratorium Antena, serta menyediakan interface bagi pengelola sistem sehingga meraka mampu melakukan monitoring secara online. Sensor yang digunakan pada alat ini sensor DHT untuk suhu dan kelembaban serta sensor CT untuk pembacaan arus listrik. Data sensor kemudian disimpan di database SQL dan dapat ditampilkan pada web browser. Keunggulan dari alat ini data dapat di ambil dalam kurun waktu yang cukup lama, karena data tersimpan dalam database manager selain itu pengelola laboratorium dengan mudah mengetahui kondisi suhu dan energy listrik yang digunakan suatu ruangan tanpa harus datang membawa alat ukur ke ruangan tersebut. Dengan adanya alat ini dapat membantu pengelola laboratorium dalam melakukan perawatan anechoic chamber.
\end{abstract}

Kata Kunci: Anechoic Chamber, Daya listrik, ,internet, monitoring,suhu, SQL

\begin{abstract}
The purpose of this tool is to build data communications for gathering information about humidity temperature conditions and using electric energy anechoic chamber in Antenna laboratory, and providing interface for system managers so that they are able to monitor online. The sensors used in this device are DHT sensors for temperature and humidity as well as CT sensors for electric current readings. Sensor data is then stored in the SQL database and can be displayed on a web browser. The advantages of this tool data can be taken in a long time, because the data stored in the database manager other than that the laboratory manager to easily determine the condition of temperature and electrical energy used in a room without having to come bring gauges to the room. With this tool can help laboratory managers in the treatment of anechoic chamber.
\end{abstract}

Keywords: Anechoic Chamber, Power electricity, internet, monitoring, temperature, $S Q L$

\section{Pendahuluan}

Laboratorium Antena dan Propagasi merupakan salah satu laboratorium di lingkungan Teknik Elektro Politeknik Negeri Padang (JTE PNP), yang berada di bawah Bidang Studi Teknik Telekomunikasi. Salah satu fungsi yang dimiliki oleh laboratorium ini adalah menyediakan sarana dalam melaksanakan pratikum yang terkait dengan propagasi gelombang radio dan elektronika telekomunikasi. Kegiatan praktikum yang dilaksanakan oleh Laboratorium Antena dan Propagasi adalah sebagai berikut :

1. Praktikum Antena

2. Praktikum Saluran Transmisi

3. Praktikum Elektronika Telekomunikasi

Selain melaksanakan kegiatan pratikum, Laboratorium antena dan propagasi JTE PNP memiliki aktivitas untuk penelitian dan pengembangan baik yang dilakukan secara individu dalam bentuk Tugas Akhir (TA) dan Proyek Akhir (PA) maupun yang dilakukan secara kelompok (Research Group). Peralatan penunjang kegiatan penelitian Laboratorium antena dan propagasi antara lain Anechoic Chamber.
Anechoic Chamber adalah ruang yang dirancang untuk medan bebas gema, yang menyerap refleksi dari suara (Zulfian dan Lindawati, 2012), fungsi dari alat tersebut dalam kegiatan penelitian untuk menguji antena (pengukuran), radar atau gangguan elektromagnetik, untuk telepon bergerak, satelit dan Tes Near Field Sites (dengan sistem positioner). Penelitian unggulan yang menggunakan Anechoic Chamber antara lain; 1) Pembuatan Antena Mikrostrip Phased Array dengan Pengaturan Fasa Menggunakan Variasi Panjang Saluran Catu, 2) Pembuatan Antena Mikrostrip Model Angka 4 Untuk Penerima Sinyal Televisi Pada Jalur UHF (Ultra High Frekuensi) dan lain-lain.

Prinsip kerja dari alat ini pada dasarnya menurut (Valis, A.G, Giulino dan H.G. dan Mendez, A.M, 1995) sifat dinding pada ruang tanpa gama dapat meredam gelombang pancar yang dibutuhkan oleh antena penerima dalam jarak tertentu yang diletakkan dalam ruangan. Peran yang dihasilkan sebagai penyerap gelombang elektromagnetik yang terdapat dalam ruangan adalah lapisan pelapis yang terdapat di 
setiap dinding ruang tanpa gema yang terbuat dari bahan penyusun yang dirancang sedemikian sehingga menyerap dan mendesipasikan setiap gelombang elektromagnetik yang masuk. Alat ini mempunyai sensitivitas yang tinggi terutama terhadap suhu kelembaban dan arus listrik. Suhu dan kelembaban untuk anechoic chamnber Laboratorium antena dan propagasi JTE PNP berdasarkan Applications and Standart JS Denki perusahaan yang membuat alat tersebut yaitu $22,8^{\circ} \mathrm{C}$ s $/ \mathrm{d} 27,1^{\circ} \mathrm{C}$ dengan kelembaban udara $70 \%$ s/d $85 \%$,jika suhu dan kelembaban udara dibawah maupun diatas ketentuan secara terus menerus akan menyebabkan kerusakan pada lem perekat absorber yang berfungsi untuk menyerap sinyal gelombang elektromagnetik, apabila lem perekat absorber pada anechoic chamber mengalami kerusakan maka akan terdapat ganguan pada pola radiasi antenna pemancar sehingga mempengaruhi hasil pengukuran pada antenna penerima, pengantian pada lem perekat absorber yang telah rusak adalah penggantian dengan material baru yang harganya relative mahal karena harus diimport. Selain itu arus listrik juga sangat mempengaruhi proses keakuratan hasil pengukuran alat ini, jika arus berada diluar dari Applications and Standart JS Denki maka dapat mempengaruhi akurasi pengukuran, untuk itu nilai arus harus dijaga agar selalu berada di batas tolerasi yang telah ditetapkan. Berdasarkan uraian diatas maka perlu adanya tindakan monitoring agar anechoic chamber ini dapat berfungsi maksimal sesuai dengan parameter-parameter ideal yang dibutuhkan.

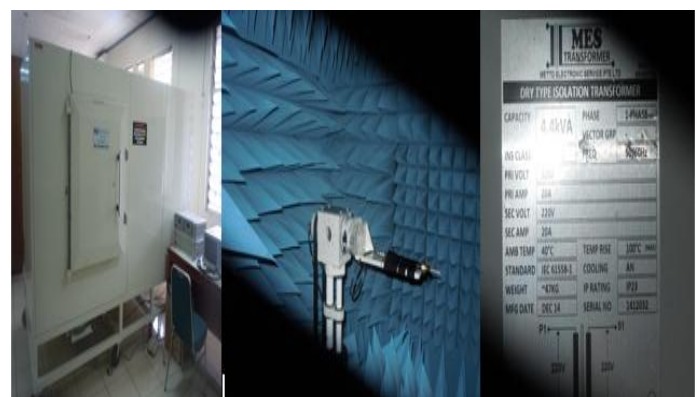

Gambar 1. Gambar Anechoic Chamber, absorber dengan antena penerima \& standar daya penggunaan Anechoic Chamber

Monitoring yang dilakukan ini haruslah memenuhi beberapa hal ketentuan dasar berupa akurasi data, efektifitas dan berkesinambungan. Data yang akurat tentu berdasarkan hasil pembacaan sensor terhadap objek yang diukur, dan efektifitas dimaksudkan pelaksanaan monitoring dapat dilakukan dimana dan kapan saja diluar lokasi objek (Anechoic Chamber), sedangkan berkesinambungan diartikan data yang diukur (arus dan suhu) secara terus menerus dapat disimpan sehingga dapat membantu pelaksana monitoring dalam mengambil keputusan untuk perawatan Anechoic Chamber agar selalu dalam kondisi optimal. Didasari keinginan terhadap tiga hal diatas (akurasi, efektifitas dan berkesinambungan) maka dibuatlah alat monitoring suhu kelembaban dan daya listrik yang dapat dibaca secara online pada anechoic chamber. Alat ini memanfaatkan sensor dht untuk suhu dan kelembaban, sedangkan untuk daya menggunakan sensor CT. Keefektifitassannya berupa penggunaan interface yang berbasis web sehingga dapat diakses kapan saja dan dimanapun berada sepanjang terdapat akses internet, sedangkan berkesinambungan data pembacaan sensor tersimpan pada database.

Penelitian tentang real time monitoring ini sebelumnya pernah dilakukan oleh Yusnan Badruzzaman pada tahun 2012, dengan menggunakan power meter PM 810 untuk penggukuran daya listrik dan harus menambahkan PM 8ECC untuk data logger dan gateway, kelebihan dari alat ini dapat membedakan beban yang dipakai antara resistif, kapasitif dan induktif akan tetapi alat ini harganya relative mahal, selain itu penelitian ini memiliki sedikit kekurangan, system transfer data dari power meter ke komputer untuk keperluan pembacaan dan analisis data memerlukan suatu software tambahan yaitu power logic power view. Selain itu penelitian yang terkait juga pernah dilakukan oleh Arief Fadhillah 2013, penelitian ini menggunakan sensor dht11 untuk pengukuran suhu dan kelembaban untuk Base Transmission Station (BTS) pada PT Telkomsel. Produk komersial yang memuat tentang program real time monitoring data ini juga telah dibuat oleh salah satu brand yang bergerak pada bidang otomasi industri yaitu Schneider Electric. Mereka meluncurkan software bernama ION ENTERPRISE. PowerLogic ION Enterprise adalah suatu perangkat lunak yang memberikan solusi manajemen daya lengkap untuk penyedia energi dan operasi industri atau komersial. Perangkat lunak ini memberikan teknik dan manajemen informasi yang mereka butuhkan untuk memotong biaya energi terkait, menghindari downtime dan mengoptimalkan penggunaan peralatan

\section{Metode Penelitian}

Pada bagian ini, dipaparkan pembahasan singkat mengenai perancangan dan implementasi sistem dan dijelaskan tentang cara kerja sistem yang terdapat dalam garis besar perancangan sistem dan diikuti dengan penjelasan tentang perangkat keras (hardware) yang terdiri dari beberapa bagian yang berfungsi untuk mengolah data. Kemudian diikuti dengan perancangan dan pembuatan perangkat lunak (software). 


\subsection{Perancangan Hardware}

\subsubsection{Rangkaian Elektronika Alat Monitoring Suhu Kelembaban dan Daya Listrik}

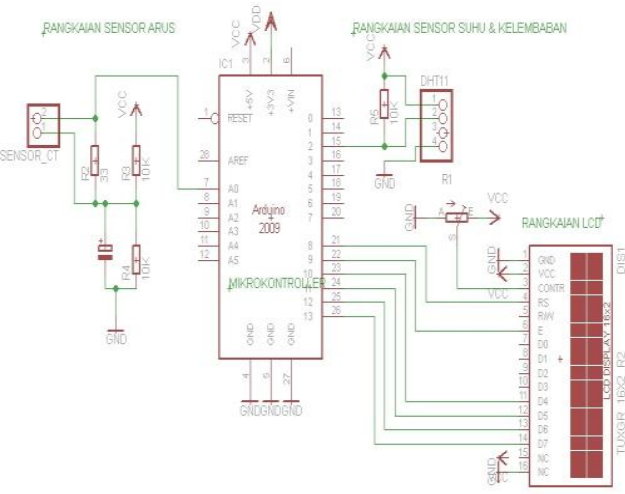

Gambar 2. Rangkaian elektronika alat monitoring suhu kelembaban dan daya listrik

Gambar 2 diatas menunjukan rangkaian elektronika dari alat monitoring suhu kelembaban dan daya listrik. Rangkaian ini dibagi menjadi lima bagian, yaitu (1) Rangkaian sensor arus . (2) Rangkaian sensor suhu dan kelembaban, (3) Rangkaian Mikrokontroler ATMega3128, (4) Rangkaian LCD .

\subsubsection{Rangkaian Sensor Arus dengan CT} Sensor

Sensor arus dirancang menggunakan CT Sensor. Sensor ini merubah besaran arus primer menjadi besaran arus sekunder dengan perbandingan tertentu dan mempunyai beda sudut fasa mendekati nilai nol pada polaritas hubungan yang sesuai (Open Energy, 2014). Medan Magnet yang terjadi pada lempengan konduktor akan ditangkap dan diubah untuk menjadi tegangan DC. Outputnya inilah yang akan diteruskan ke PORT ADC mikrokontroller yaitu A0 yang sebelumnya melewati beberapa komponen pendukung. Kemudian output ini akan dikonversi kedalam satuan ampere sesuai dengan arus yang terbaca pada alat ukur tang ampere. Berikut ini adalah tabel 1 yang menunjukan hasil konversi tersebut.

Tabel 1. Perbandingan Nilai ADC dengan Arus Terukur

\begin{tabular}{lclc}
\hline $\begin{array}{l}\text { Nilai } \\
\text { ADC }\end{array}$ & $\begin{array}{l}\text { Arus } \\
\text { Terukur (A) }\end{array}$ & $\begin{array}{l}\text { Nilai } \\
\text { ADC }\end{array}$ & $\begin{array}{l}\text { Arus } \\
\text { Terukur }(\mathrm{A})\end{array}$ \\
\hline 512 & 0.00 & 744 & 2.81 \\
533 & 0.15 & 786 & 3.25 \\
561 & 0.61 & 829 & 3.75 \\
592 & 1.02 & 873 & 4.19 \\
626 & 1.50 & 918 & 4.68 \\
663 & 1.82 & 964 & 5.03 \\
\hline
\end{tabular}

2.2.3 Implementasi Arduino Ethernet Shield dengan Rangkaian Elektronika Alat Monitoring Suhu Kelembaban dan Daya Listrik

Arduino pada penelitian ini digunakan arduino UNO dengan mikrokontroller ATMEGA328 ditambah dengan Ethernet shield sebagai penghubung arduino ke jaringan computer. Untuk menjadikan arduino sebagai webclient, maka arduino harus dicoding terlebih dahulu sesuai dengan tata cara pengkodingan arduino untuk menjadi webclient sehingga arduino bisa mengirimkan data dari rangkaian sensor arus dan sensor suhu ke server dan semua data yang dikirim oleh rangkaian sensor arus dan sensor suhu akan disimpan di dalam database.

\subsection{Perancangan Perangkat Lunak (Software)}

Dalam perancangan dan pembuatan perangkat lunak (software) pada penelitian ini, komunikasi sensor arus dengan mikrokontroler dan seluruh proses menggunakan bahasa $\mathrm{C}$ software arduino IDE. Sedangkan pada bagian komunikasi mikrokontroler dengan servermenggunakan bahasa pemograman PHP untuk kemudian dikirim dan disimpan pada database yang menggunakan aplikasi PHP MyAdmin, aplikasi ini ditampilkan melalui web browser menggunakan software PHP, Ajax dan Java script.

\subsubsection{Diagram Alir Perangkat Lunak (Software)}

Gambar 3 berikut ini adalah diagram alir program pada perangkat lunak

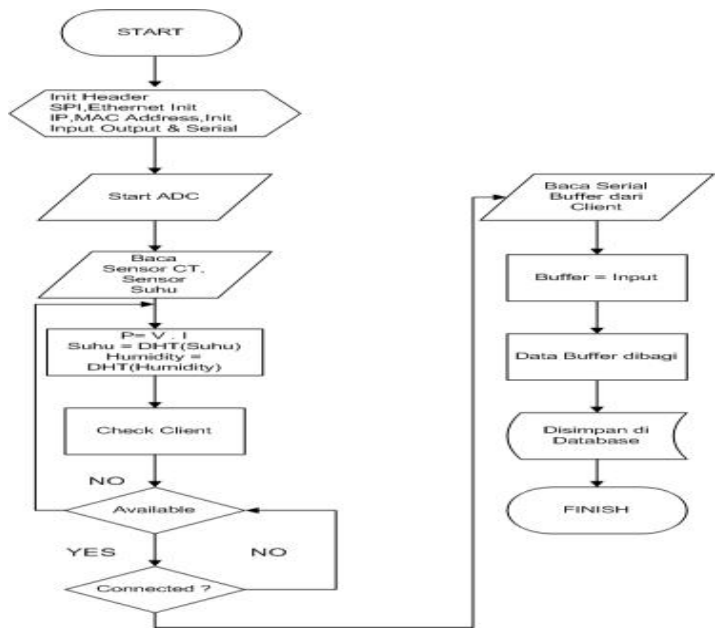

Gambar 3. Diagram alir perangkat lunak (Software)

Dari diagram alir diatas dapat dijelaskan, pertama dilakukan pendeklarasian Ethernet, IP dan MAC address dari ethernet shield serta baud rate serial 9600. Data yang terbaca dari sensor suhu adalah 
data digital sedangkan yang keluar dari sensor arus adalah berupa data analog, dengan demikian arduino yang memiliki rangkaian ADC ( Analogue Digital Converter ) akan mengkonversi data analog tersebut menjadi data digital yang akan ditampilkan pada analog read serial. Selain membaca dan menampilkan nilai serial dari sensor suhu dan arus beban terbaca, arduino UNO merupakan alat kontrol dari hasil yang di keluarkan, dimana nilai arus yang terbaca tersebut akan di kalikan dengan ADC. Adapun perumusan yang di kalikan dengan ADC didapat dari teori regresi, sehingga nilai kuadrat kesalahan data menjadi minimum, sehingga meskipun akan ada perbedaan tiap kenaikan data, setelah di berikan rumus yang di dapat akan mendekati presisi. dengan sumber data perbandingan antara data terukur menggunakan alat tang ampere dengan data pembacaan sensor. Arus yang telah dikonversi kemudian dimasukan ke persamaan matematis untuk data aktif :

$$
P=V . I(k W)
$$

Dimana $V$ adalah tegangan jala-jala listrik $=220 \mathrm{~V}$, sedangkan $\cos \theta$ sudut antara arus dan tegangan $=0$, (Pabla,AS dan Abdul Hadi.,1994). Setelah itu data serial dari rangkaian arus dan suhu dikirimkan ke database melalui ethernet shield.

\section{Hasil dan Pembahasan}

Berdasarkan spesifikasi dan sistem kerja yang dijelaskan sebelumnya, maka selanjutnya dilakukan pengujian terhadap sistem tersebut. Tujuan dari pengujian ini adalah untuk mengetahui apakah sistem yang telah dibuat sudah sesuai dengan yang telah direncanakan sebelumnya.

\subsection{Pengujian Sensor Arus dan Sensor Suhu Kelembaban}

Pengujian hasil pembacaan sensor arus dengan arus terukur menggunakan alat ukur tang ampere yang telah dikalibrasi. Tujuan dari pengujian ini adalah untuk mengetahui ketelitian sensor terhadap besaran listrik yang diukur. Untuk mengetahui deviasi error antara data pembacaan sensor dengan data terukur pada alat ukur tang ampere digunakan persamaan sebagai berikut.

Error $=\frac{\text { Selisih nilai sensor dengan nilai alat ukur }}{\text { nilai alat ukur }} \times 100$

Hasil pengujian sensor arus dapat dilihat pada gambar 4 dan gambar 5 berikut ini.

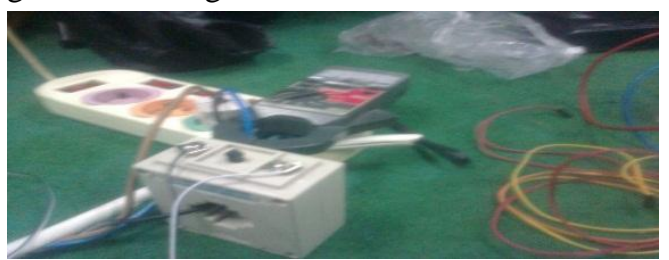

Gambar 4. Pengujian sensor arus

\begin{tabular}{|c|c|c|c|c|c|}
\hline $\begin{array}{l}\text { Jumlah } \\
\text { Lampu } \\
\text { (buah) }\end{array}$ & Dava (Watt) & Data ADC & $\begin{array}{l}\text { Arus Terukur } \\
\text { Dengan Tang } \\
\text { Ampere (A) }\end{array}$ & $\begin{array}{l}\text { Arus Terukur } \\
\text { Dengan } \\
\text { Sensor } \\
\text { (Ampere) }\end{array}$ & Error \\
\hline Tanpa beban & 0 & 512 & 0.00 & 0.00 & 0.00 \\
\hline 1 & 100 & 533 & 0.15 & 0.20 & 0.05 \\
\hline 2 & 200 & 561 & 0.61 & 0.60 & .0 .01 \\
\hline 3 & 300 & 592 & 1.02 & 0.98 & .0 .04 \\
\hline 4 & 400 & 626 & 1.50 & 1.48 & .0 .02 \\
\hline 5 & 500 & 663 & 1.82 & 1.80 & .0 .01 \\
\hline
\end{tabular}

Gambar 5. Hasil pengujian sensor arus

Dari hasil pengukuran dapat dilihat nilai rata-rata error yang dihasilkan cukup kecil sehingga rancangan sensor arus layak digunakan. Berikutnya pada gambar 6 ditampilkan pengujian hasil pembacaan sensor suhu dan kelembaban dengan alat thermometer AMT-13 yang telah di kalibrasi.

\begin{tabular}{|c|c|c|c|c|c|c|}
\hline Waktu & $\begin{array}{l}\text { Suhu Terukur } \\
\text { dengan } \\
\text { Thermometer } \\
\text { AMT-13 }\end{array}$ & $\begin{array}{l}\text { Suhu } \\
\text { Terukur } \\
\text { dengan } \\
\text { Sensor }\end{array}$ & Error & $\begin{array}{l}\text { Kelembaban } \\
\text { Terukur } \\
\text { dengan } \\
\text { Thermometer } \\
\text { AMT-13 }\end{array}$ & $\begin{array}{l}\text { Kelembaban } \\
\text { Terukur } \\
\text { dengan } \\
\text { Sensor }\end{array}$ & Error \\
\hline Pagi & $24^{\circ} \mathrm{C}$ & $24.49^{\circ} \mathrm{C}$ & 0.02 & $68 \%$ & $68,42 \%$ & 0.06 \\
\hline Siang & $26^{\circ} \mathrm{C}$ & $26.699^{\circ} \mathrm{C}$ & 0.02 & $71 \%$ & $71,61 \%$ & 0.08 \\
\hline
\end{tabular}

Gambar 6. Hasil pengujian sensor arus

Dari hasil pengukuran dapat dilihat nilai rata-rata error yang dihasilkan cukup kecil sehingga rancangan sensor suhu dan kelembaban layak digunakan.

\subsection{Hasil Pengujian Secara Keseluruhan}

Pengujian sistem ini dilakukan pada Anechoic Chamber diruangan laboratorium antenna dan propagasi politeknik negeri padang Sistem ini dibangun dengan dengan database server yang berada di ruangan puslabkom politeknik negeri padang dan webclient. Untuk webclient digunakan arduino UNO ATMega328 ditambah dengan rangkaian sensor arus dan suhu kelembaban serta Ethernet shield yang berfungsi untuk menghubungkan arduino ke jaringan komputer, sehingga semua data yang ditangkap oleh rangkaian sensor bisa dikirim secara online dan disimpan dalam database server untuk dianalisa.

Untuk pengujian arduino sebagai webclient menggunakan protokol HTTP, arduino berhasil dijadikan sebagai webclient, dibuktikan dengan melihat dari database yang ada pada server. Saat arduino, ethernet shield dan rangkaian sensor mengirimkan data akan langsung masuk ke database server dan ditampilkan di dalam web browser secara realtime. Tampilan dari web browser dan database-nya dapat dilihat pada gambar 7 . 


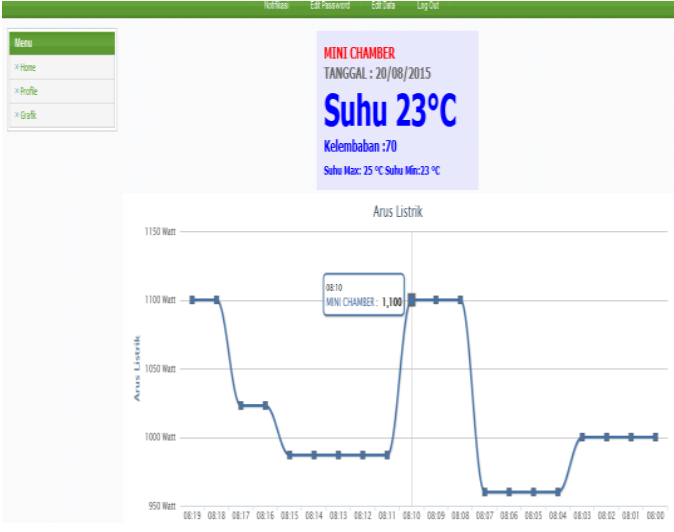

Gambar 7. Tampilan GUI web browser akuisisi data daya dan suhu kelembaban Anechoic Chamber

Pada gambar 7 diatas dilihat data yang dikirim oleh arduino sebagai webclient. Pada label terlihat informasi tanggal, suhu dan kelembaban serta suhu maksimal dan minimal Anechoic Chumber .Untuk grafik yang berwarna biru merupakan data daya pemakian Anechoic Chamber per satuan waktu (detik), Berdasarkan grafik diatas dapat diambil data sensor yang dikirim ke web browser, yang disajikan kedalam tabel 2.

Tabel 2 Data Daya, Suhu dan Kelembaban Pada Anechoic Chamber

\begin{tabular}{ccccc}
\hline No & Waktu & $\begin{array}{c}\text { Suhu } \\
{ }^{\circ} \mathrm{C}\end{array}$ & $\begin{array}{c}\text { Kelembaban } \\
\%\end{array}$ & $\begin{array}{c}\text { Daya } \\
\text { Watt }\end{array}$ \\
\hline 1 & 08.00 & 23 & 70 & 1000 \\
2 & 08.01 & 23 & 69 & 1000 \\
3 & 08.02 & 24 & 70 & 1000 \\
4 & 08.03 & 25 & 70 & 1000 \\
5 & 08.04 & 25 & 69 & 960 \\
6 & 08.05 & 23 & 70 & 960 \\
7 & 08.06 & 23 & 70 & 960 \\
8 & 08.07 & 23 & 69 & 960 \\
\hline
\end{tabular}

Dari tabel 2 dapat dilihat pembacaan sensor pada alat monitoring suhu kelembaban dan daya listrik yang dipasang di laboratorium antenna dan propagasi pada anechoic chamber sesuai dengan tampilan grafik. Data yang ditampilkan di dalam web browser tidak akan langsung muncul, karena data terlebih dahulu masuk ke dalam database, kemudian data akan diparsing ke dalam web browser, data didalam database PhpMyadmin dapat dilihat pada gambar di bawah ini

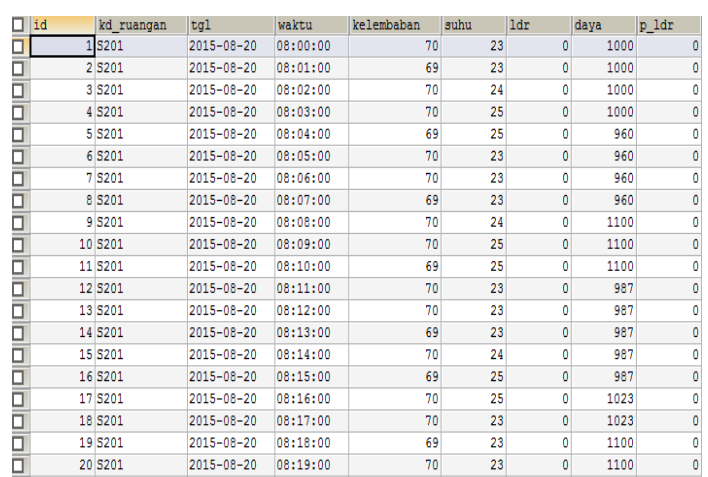

Gambar 8. Tampilan database di server

Pada gambar 8 diatas ditampilkan data suhu kelembaban dan daya listrik yang dikirim ke database, terlihat pada gambar 8 data yang dikirim ke web browser sama dengan data yang ada di dalam database, yaitu data pada database PhpMyadmin ini yang akan diparsing ke dalam web browser dengan bentuk tampilan grafik. Untuk pengujian arduino sebagai webclient dikatakan berhasil karena arduino sebagai webclient telah berhasil mengirimkan data suhu kelembaban dan daya listrik yang ditangkap oleh rangkaian sensor untuk di kirim ke server, yang selanjutnya data data suhu kelembaban dan daya listrik akan di tampilkan ke dalam web browser dalam bentuk grafik. Pada gambar 9 dapat dilihat alat terpasang pada anechoic chamber yang terhubung ke server politeknik negeri padang.

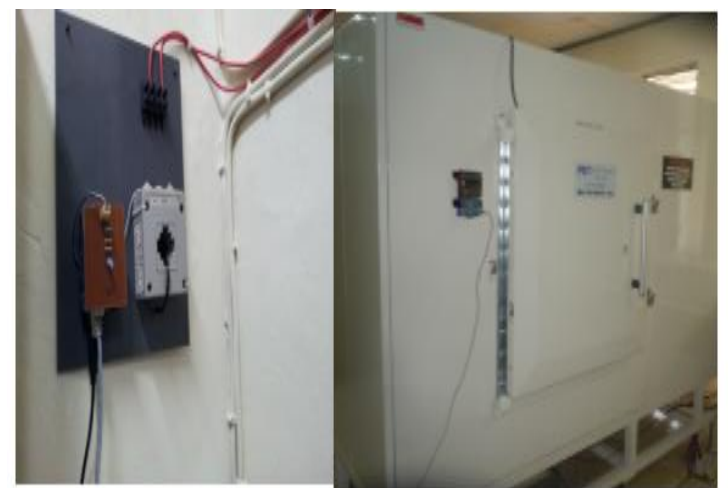

Gambar 9. Alat terpasang pada Anechoic Chamber Laboratorium Antena dan Propagasi

\section{Kesimpulan}

Kesimpulan yang didapat dari penelitian ini adalah sebagai berikut .Pengujian Alat monitoring pada Anechoic Chamber berhasil dilakukan terbukti dengan data suhu kelembaban dan daya listrik pada tempat penelitian ini dilakukan, dapat dikirim oleh ke server, dibuktikan dengan data data suhu kelembaban dan daya listrik pada yaitu phase Suhu $=24^{\circ} \mathrm{C}$ Kelembaban $=70 \%$ dan Daya $=1000$ watt terkirim ke web server dan data disimpan dalam database. 


\section{Daftar Pustaka}

Zulfian and Lindawati (2012), Assessment of Acoustic Performance of Anechoic Chamber at Acoustic Laboratory in Syiah Kuala, University International Journal of Basic \& Applied Sciences IJBAS-IJENS Vol:12 No:06

Valis, A.G, Giulino, H.G., and Mendez, A.M (1995). The anechoic chamber at the Laboratory de Acoustica Luminot ocnia CIC, Applied acoustics, 44, 79 - 94 .

Yusnan Badruzzaman. (2012). Real Time Monitoring Data Besaran Listrik Gedung Laboratorium Teknik Sipil Politeknik Negeri Semarang. Tugas Akhir, Semarang: Politeknik Negeri Semarang

Arif Fadilah. (2013). The Data Akuisisi System Design Based at Base Transmision Station (BTS) PT. TELKOMSEL. Thesis. Padang: Andalas University.

Open Energy, (2014), CT sensors - Interfacing with an Arduino, www.openenergymonitor.org, accessed August 07, 2014

Pabla,AS.,Abdul Hadi. (1994). Sistem Distribusi Daya Listrik , Jakarta:Erlangga

Srividyadevi P., Pusphalatha D.V. and Sharma P.M, (2013), Measurement of Power and Energy Using Arduino, Research Journal of Engineering Sciences Vol. 2(10), 10-15 